\title{
USE OF THE FINITE ELEMENT METHOD TO DESIGN THE PROPERTIES OF SHAPED JOINTS MADE OF COMPOSITE MATERIALS
}

\author{
Andrzej Dylewski ${ }^{1}$, Waldemar Łogin ${ }^{1}$
}

1 PZL Mielec / a Sikorsky Company, ul.Wojska Polskiego 3, 39-300 Mielec, e-mail: andrzej.dylewski@Imco.com, waldemar.login@Imco.com

Received: 2017.11.16

Accepted: 2018.04.04

Published: 2018.06.01

\begin{abstract}
Polskie Zaklady Lotnicze in Mielec within the framework of the BloStEr project implemented in the sectoral program INNOLOT develops technology whose main idea is to be able to connect parts into structures through the use of specially designed shaped joins. The article presents the results of numerical analyzes of the selected shape joint made of long fiber composite and verification of analyzes on real object. The second part of the paper presents the results of performed numerical analyzes, which investigated the influence of the change of the layer system on the properties of the joint, in particular the opening force and deformation phenomena of the working elements.
\end{abstract}

Keywords: FEM, composites, shaped connections, laminate optimization.

\section{INTRODUCTION}

Within the framework of the BloStEr project, Polskie Zaklady Lotnicze w Mielcu develops an innovative concept of building aerostructures, produced without the use of traditional forms of joining individual elements such as rivets, screws, bonding, etc. The main assumption is the design and fabrication of integral parts which, thanks to the application of so-called locks will be connectable together. The premise is that there is a significant reduction in elements in the structure and minimization of the riveting, which, as experience shows, is a time consuming process and is a major source of human error during assembly stage. The works in the project refer to thinwalled metal and composite structures. For the latter, the problem is much more difficult, as the final result in the form of a shape connection is influenced by many more factors. It can be stated that the final properties of the joint and the entire composite structure are the result of inaccuracies that appear during the manufacturing process.

In the case of composite materials connection work you can be influenced not only by changing the geometry (similar like in metal-metal connection) [2] but also by the design of the same material, in particular of a layer system. This is a fundamental feature that differ composites materials from metal technology. Changes in the orientation of the layers affect the properties of the joint made of fibrous composite and allow for quite different characteristics using the same material. This effect can also be accidental, resulting for example from human errors during laminating.

In the project three criteria were adopted to evaluate the developed solutions : opening force, closing force and the ratio of these forces called efficiency. In fact, the value of these forces are significantly affected by manufacturing inaccuracies, which cannot be neglected in any way, especially when a large thin-walled structure is taken into account. One of them are random angles during layering. Angles of layers have direct influence onto matrix of stiffness $[7,9]$ so also for deformation under load. In the BloStEr project a series of connections has been developed, and in practice each of them has own characteristic. There was a discrepancy between the experimental results and the results achieved from numerical 


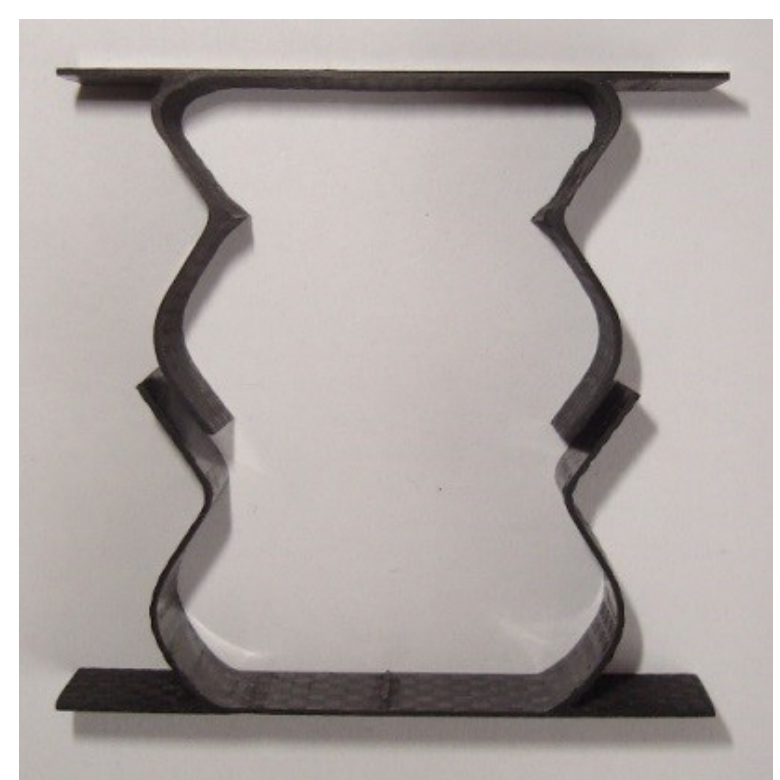

Fig. 1. View of connection model

analysis. Their value was different for each geometry. After analyzing the results, the influence of geometric inaccuracies between the working surfaces of the joints was highlighted as one of the main reasons for the observed discrepancies. In the case of composites, the manufacturing process is much more complex than the metal components, which directly affects the probability of achieving other properties than planned.

The first part of the paper presents the results obtained for one of the analyzed connection in the project. The second part presents the results of the performed numerical analyzes on the selected shape, where the influence of the layer system on the properties of the connection was studied.

\section{ANALYZED SHAPED CONNECTION}

Polskie Zaklady Lotnicze, in cooperation with prof. T. Sadowski's team from Lublin University of Technology and Wit-Composites, as one of the proposals developed a solution of the composite shaped connection presented in Fig. 1. A number of numerical analyzes have been performed for him by refining the shape and exploring properties for the selected layered systems.

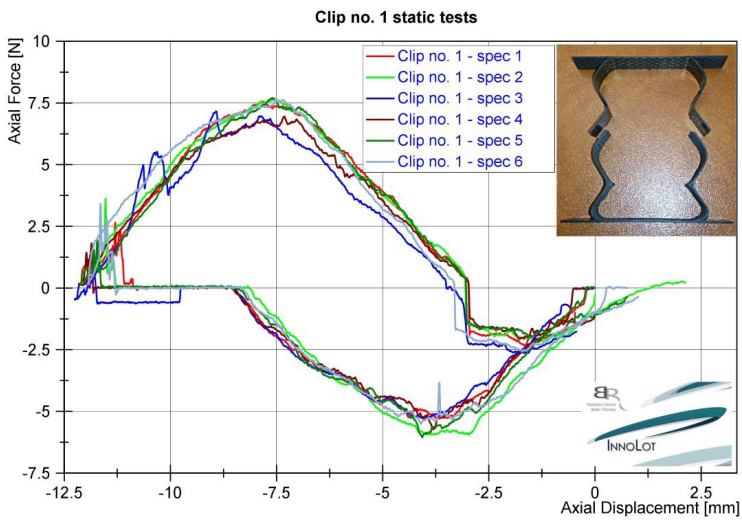

Fig. 2. Results of experimental studies performed on the join

In the next step, this connection was made and experimental studies were performed, the results of which are shown in Fig. 2.

The results of numerical analysis were compared with the laboratory experiment especially examining the opening and closing forces. Results are presented in Table 1.

As can be seen for the tested connection, there was a discrepancy between the results obtained up to $24 \%$ for the closing force. Analyzing their cause, the geometrical inaccuracies in the composite joint models were observed. Performed analysis of the cross-sectional images of the connection showed, that there is no match in some area between the working surfaces of the joint. Observed inaccuracies have been identified as one of the main factors affecting the resulting discrepancies between the numerical results and the laboratory test. When analyzing the source of geometric errors, the following potential factors were identified: geometric inaccuracies in the tooling, deviations in the part resulting from the polymerization shrinkage, and possible errors in layers orientation.

In the next stage of the study, numerical analysis of the effect of change the layout of the layers in its working elements on the properties of the joint have been performed.

Table 1. Results of numerical and experimental studies for analyzed connection

\begin{tabular}{|c|c|c|c|}
\hline & FEM result & Test result (average) & Difference \\
\hline Opening force $F_{\text {op }}[N]$ & 8,35 & 7,4 & $11 \%$ \\
\hline Closing force $F_{c 1}[N]$ & 7,39 & 5,6 & $24 \%$ \\
\hline Efficiency $F_{\text {op }} / F_{c 1}$ & 1,13 & 1,32 & $17 \%$ \\
\hline
\end{tabular}




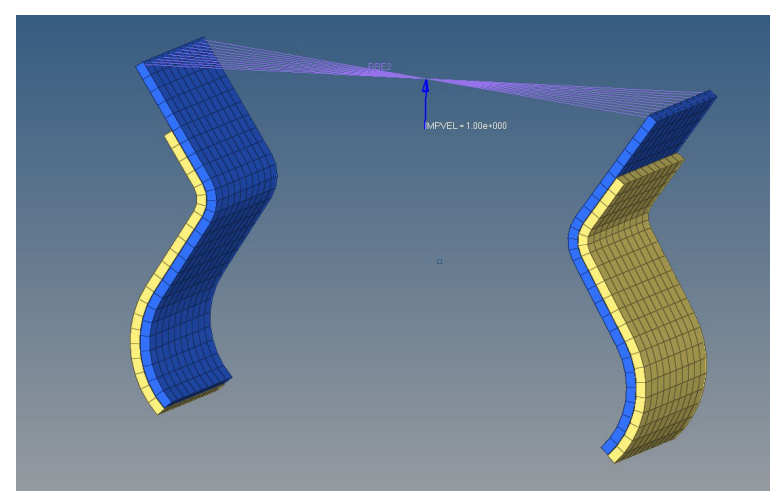

Fig. 3. Discrete model of the composite shaped connection

\section{EXPERIMENT METHODOLOGY}

Based on the geometry of the connection shown in Fig. 1 and the results presented earlier, a numerical model was developed for layer research. The RADIOSS module in HyperWorks software was used for the analysis. This module uses the explicit type of analysis and thus can calculate nonlinear and dynamic phenomenon.[10]

The closing / opening process was treated as a dynamic phenomenon - variable over time, assuming a fairly large time interval. Movement of the system was achieved by assigning the speed of a node attached to a rigid MPC element.

The boundary conditions consisted of the fixed extremes of the lower part of the joint (the so-called female part) - marked in yellow on the Fig. 3 and all degrees of freedom (translational and rotational) were taken away.

The edges of the components of the upper part of the connection (the so-called male part) - marked blue on fig. 3, were bound to the RBE2 rigid element, while they were given the opportunity to translate and rotate in the $\mathrm{X}$ and $\mathrm{Y}$ directions. Movement of the system was achieved by assigning the velocity to the node attached to the rigid element (blue arrow IMPVEL on the Fig. 3). The speed was $1 \mathrm{~m} / \mathrm{s}$.

For the construction of the discrete grid, quads with 4-node with 5 degrees of freedom were used. The integration procedure for 4 integral points (Gauss) was used.

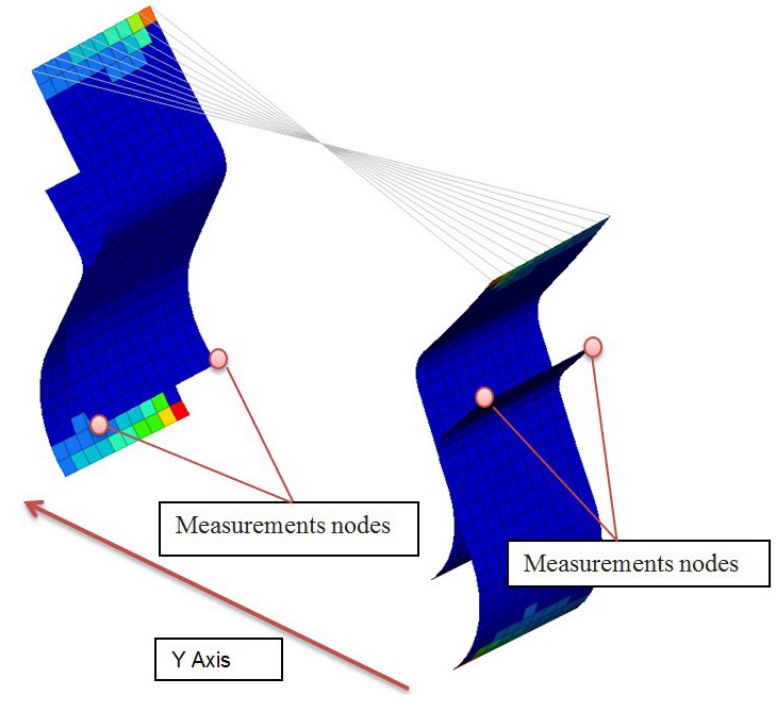

Fig. 4. Twisting measure method

Contact was modeled using Type7 general contact elements with friction coefficient 0.01 . Analyzes have been made for a connection made from unidirectional carbon composite whose properties are shown in Table 2.

Four different layered laminate layouts were used for the analysis. In each case, the working elements of the connections were made up of seven layers. On the actual object average laminate thickness was $0.65 \mathrm{~mm}$. The model was assumed to be $0.7 \mathrm{~mm}$ assuming that the thickness of the single layer after curing was $0.1 \mathrm{~mm}$. The effect of the layer system on the opening force for the joint was analyzed.

The following laminated systems were adopted:

- Reference system with orientation of all layers $0^{\circ}$.

- Symmetric layout with 4-layer rotated by $20^{\circ}$ in configuration $\left[0,(20)_{2}, 0,(20)_{2}, 0\right]$.

- Symmetric layout $45^{\circ}$, with neutral layer being set at $0^{\circ}$.

- Non symmetric layout with $-45^{\circ}$ for male connecction elments and $45^{\circ}$ for female connections elements.

Apart from the value of the opening force, there was also considered the twisting of the working surfaces of the connections for individual cases and the influence of this phenomenon

Table 2. Material properties

\begin{tabular}{|c|c|c|c|c|c|c|c|c|}
\hline $\mathrm{E}_{11}$ & $\mathrm{E}_{22}$ & $\mathrm{v}_{12}$ & $\mathrm{G}_{12}$ & $\mathrm{X}_{\mathrm{t}}=\mathrm{X}_{\mathrm{c}}$ & $\mathrm{Y}_{\mathrm{t}}=\mathrm{Y}_{\mathrm{c}}$ & $\mathrm{S}$ & Density & Layer thickness \\
\hline $\begin{array}{c}179,98 \\
{[\mathrm{GPa}]}\end{array}$ & $5,69[\mathrm{GPa}]$ & 0,38 & $4,34[\mathrm{GPa}]$ & $\begin{array}{c}1400,54 \\
{[\mathrm{MPa}]}\end{array}$ & $\begin{array}{c}19,11 \\
{[\mathrm{MPa}]}\end{array}$ & $90[\mathrm{MPa}]$ & $1400 \mathrm{~kg} / \mathrm{m}^{3}$ & $0,1 \mathrm{~mm}$ \\
\hline
\end{tabular}


Table 3. Achieved results

\begin{tabular}{|c|c|c|c|c|}
\hline Layout case & Reference $\mathbf{0}^{\circ}$ & Symmetric with $\mathbf{2 0}^{\circ}$ & Symmetric with $\mathbf{4 5}^{\circ}$ & ${\text { Non symmetric } \mathbf{4 5}^{\circ}}^{\circ}$ \\
\hline Model name & 0_stopni & 20_stopni & 45_stopni_symetria & 45_stopni \\
\hline Openning force & $6,56[\mathrm{~N}]$ & $6,43[\mathrm{~N}]$ & $3,82[\mathrm{~N}]$ & $3,77[\mathrm{~N}]$ \\
\hline $\begin{array}{c}\text { Maksimal force in in } \mathbf{Y} \\
\text { axis direction }\end{array}$ & $1,99[\mathrm{~N}]$ & $2,03[\mathrm{~N}]$ & $1,77[\mathrm{~N}]$ & $1,58[\mathrm{~N}]$ \\
\hline Twist of male part & $0,001[\mathrm{~mm}]$ & $0,04[\mathrm{~mm}]$ & $0,1[\mathrm{~mm}]$ & $0,31[\mathrm{~mm}]$ \\
\hline Twist of female part & $0,002[\mathrm{~mm}]$ & $0,037[\mathrm{~mm}]$ & $0,13[\mathrm{~mm}]$ & $0,3[\mathrm{~mm}]$ \\
\hline
\end{tabular}
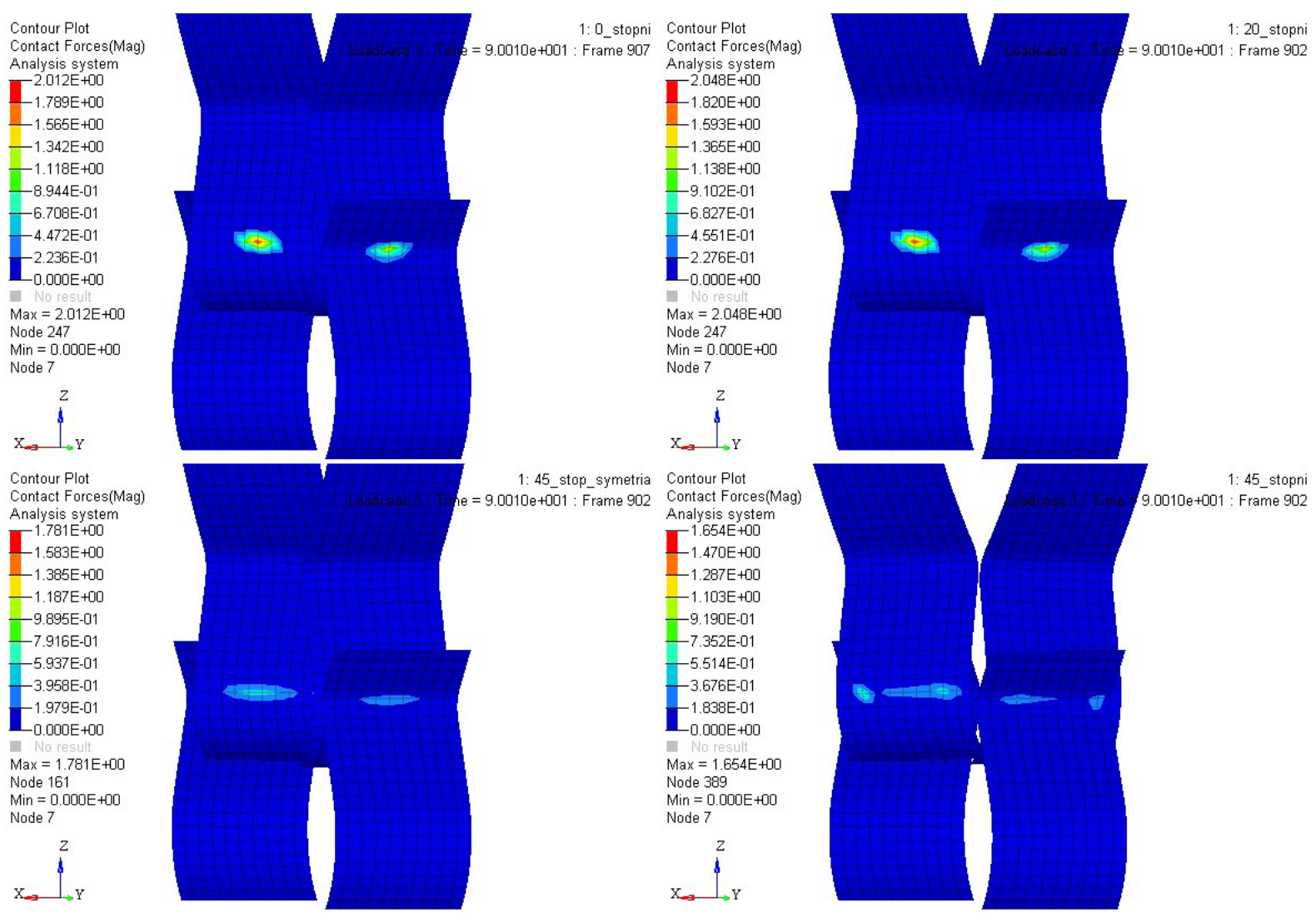

Fig. 5. Contact force distribution for each case of layers arrangement. Cases names as in Table 3

on its work. These distortions are directly related to the layer system and the behavior of the composite material. As a measure of twisting was assumed the displacement difference between the two extremes of the free end of working joint surfaces in the connection was measured on the "Y" axis of the global coordinate system, Fig. 4.

\section{RESULTS AND DISCUSSION}

As a result of the analyzes, the results presented in Table 3 were obtained.

Analyzing the results of the research, it can be observed that by changing the layer system one can control the values of the opening forces. In the case of the analyzed material, which is char- acterized by a high module along the fibers, the force value can be controlled to a large extent, reaching up to $50 \%$. It should be noted that such phenomena, in the case of analyzed connections may be undesirable. Changing the joint properties affects the strength of the structure and its functionality. Nevertheless, if a more flexible joint is to be developed, the layer system should be considered as a parameter that controls its properties.

The results of the analyzes also provide important information on the need to accurately preserve the designed orientation of individual layers. Inconsistencies in this regard, for example, at the manufacturing stage of parts, can result in a reduction in the bearing capacity of the shape 


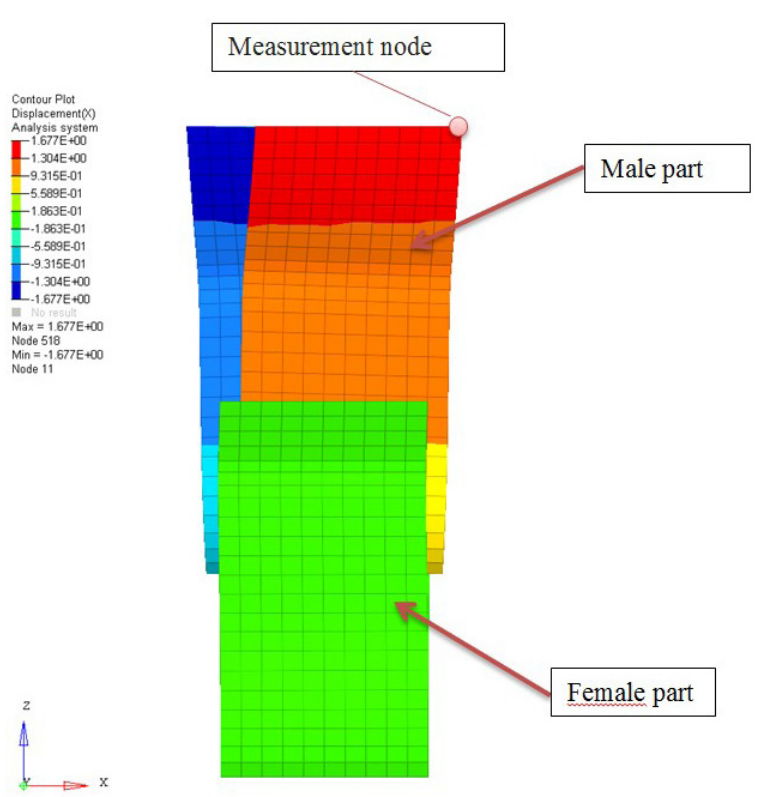

Fig. 6. Rotation of the working elements of the connection around the " $\mathrm{Z}$ " axis during opening

connection, which is completely contrary to what the designer originally assumed.

In the case of connections made of unidirectional tapes, for layered systems with a laminating angle different from zero, the phenomenon of twisting of the working surfaces under the influence of the opening force is observed. This is due to the directional rigidity of the composite material. Deformations in the direction of the "Y" axis and change in contact stress value and distribution are observed as the result. During the opening of the connection, the geometry of the mating surfaces changes, what affects the friction force. As observed during the analysis, the consequence of rotation of the laminate is the change in contact forces between the connection elements. On the basis of numerical analysis it can be observed that as the angle of rotation of the layers grow up, the stress concentration points and distribution of contact forces are changed, Fig. 5.

The values and nature of contact forces affect the tribological properties of the connection. It can be concluded that the use of unidirectional tapes with $0^{\circ}$ layer orientation will increase the wear of contact areas in the connection. This is so important that in the case of heavily loaded connections, the turnover of the laminate should be considered, at the expense of a decrease in its carrying capacity. Another observed phenomenon caused by rotation of the layers is the rotation of the connection ele- ments around the "Z" axis. Figure 6 shows the displacement observed for the most extreme analyzed case, i.e. for the asymmetric system where the layers are rotated by $45^{\circ}$.

During opening process, the upper part moves in the direction of the " $X$ " axis. In the analyzed case the connection width was $10 \mathrm{~mm}$ and the maximum displacement along the axis was 1.7 $\mathrm{mm}$. The observed phenomena can adversely affect constructions with much longer connection elements. The joint is twisted, which can affect the contact forces and uneven work during opening.

\section{CONCLUSIONS}

In the presented case experimentally analyzed connection made of composite material, the main cause of the discrepancy between numerical values and the test was the geometrical differences between the CAD model and the real element. This is one of the factors that must be taken into account when designing components and tooling. Another parameter that can significantly influence the work of such elements is the real layers orientation in the part.

As numerical analysis has shown, the rotation of layers in the laminate leads to a change in the carrying capacity of the joint. The analyzed symmetrical systems cause the distribution of contact force locally focused, with a distinct maximum. It can be assumed that the connections thus constructed will be more weary at the concentration points during opening. In the case of an asymmetrical system, it can be observed that the stresses are dispersed over the entire length of the joint, and hence will be more resistant to friction wear.

The phenomena observed during the analysis that affect the work of the connection are the twisting of its working parts. The numerical model deliberately assumed the possibility of rotation around the " $Z$ " axis in the male part. This effect is visible in the form of displacement, whose value in the analyzed case was $1.7 \mathrm{~mm}$. This is significant and this should be taken into account when designing a connection, as this can make it difficult to disassemble components.

When designing a connection for which a reduction in the opening force is required, the most interesting solution from the analysis seems to be an asymmetrical $45^{\circ}$ system. Its disadvantage, in the case of long connections, may be the deformation of the lock elements, which in turn will make it difficult to disconnect the parts. 
The work of the analyzed composite shaped connection is a complex phenomenon. Its work characteristics, properties and forces in the connection are influenced by many factors:

- Type of layer system - symmetrical / asymmetrical.

- Orientation of layers in the laminate - as the angle increases, the opening force decreases.

- Change of value and distribution of contact forces depending on the orientation of the laminate.

- Deformation of the working elements of the connection, which in the case of longer connections should be taken into account during the design.

The next step will be fabrication of the test models with analyzed layer configuration and verification of observed phenomena on real parts to validate the FEM model.

\section{ACKNOWLEDGEMENT}

Financial support of the National Centre for Research and Development (Poland) - Project "Block Structures - Mechanical joining innovations to replace conventional fasteners in aerostructures", contract No INNOLOT/I/5/ NCBR/2013 is gratefully acknowledged.

\section{REFERENCES}

1. J. Gajewski, P. Golewski, T. Sadowski, Geometry optimization of a thin-walled element for an air structure using hybrid system integrating artificial neural network and finite element method, Composite Structures 2017, Pages 121-127.

2. T. Sadowski, P. Golewski, The influence of geometrical parameters in socket - pin connection on the value of opening force, Archives of metallurgy and materials 2015, Pages 2743-2750.

3. J. Jakubowski, Uogólnienia metody elementów skończonych w inżynierskich symulacjach numerycznych ośrodka nieciągłego i dyskretnego, Górnictwo i Geoinżynieria 2010, Volume 2, Pages 325-340.

4. A.Bondyra, P.Gotowicki, Statical analysis of experimental results in the in plane shear test for a cross-ply vinylester-carbon laminate, Journal of KONES Powertrain \& Transport 2010, Pages 41-49.

5. A. Sawczuk, T. Sadowski, On Anisotropic Continuous Damage of Plates in Flexure, Engineering Structures, 1983, vol.5, $234-238$.

6. A. Boczkowska, G. Krzesiński, Kompozyty i techniki ich wytwarzania, Oficyna Wydawnicza Politechniki Warszawskiej Warszawa 2016.

7. G. Rakowski, Z. Kacprzyk, Metoda Elementów Skończonych w mechanice konstrukcji, Oficyna Wydawnicza Politechniki Warszawskiej Warszawa 2016.

8. S. Ochelski, Metody doświadczalne mechaniki kompozytów konstrukcyjnych, Wydawnictwo Naukowo-Techniczne, Warszawa 2004.

9. R.C. Wetherhold, Mechanics of Laminated Structures. Composites Engineering Handbook. New York 1997.

10. HyperWorks HTML Documentation. 